\title{
Escolarização da sexualidade no estado de Goiás: o que mostram as dissertações e teses ${ }^{1}$
}

\section{The schooling of sexuality in the state of Goias: what PhD theses and Master dissertations show}

\author{
Aline da Silva Nicolino ${ }^{2}$ \\ Marlucy Alves Paraíso
}

\begin{abstract}
RESUMO
Este artigo tem como objetivo analisar o que dizem as dissertações e teses sobre o processo de escolarização da sexualidade em Goiás. Por um lado, mostramos o que as produções estudadas dizem sobre os ensinamentos transmitidos nas escolas públicas sobre o tema e, por outro lado, analisamos como a sexualidade na escola é abordada nas produções científicas do estado. Para a escolha das investigações a serem estudadas, estabelecemos como critérios terem sido defendidas até 2012, pensadas ou realizadas no contexto escolar do estado de Goiás e que tratassem da sexualidade na escola. Ficou evidente neste estudo que a sexualidade vem despertando interesse, sobretudo, de profissionais dos campos da saúde e da educação, que divergem sobre quais "saberes" devem ser ensinados e sobre quem pode ensinar o tema na escola, disputando as melhores formas para escolarizar a sexualidade.
\end{abstract}

Palavras-chave: escolarização da sexualidade; sexualidade na escola; a produção sobre sexualidade na escola em Goiás.

DOI: $10.1590 / 0104-4060.36548$

1 Pesquisa financiada pela Fundação de Amparo à Pesquisa do Estado de Goiás (FAPEG), edital $n^{\circ} 09 / 2012$

2 Universidade Federal de Goiás. Faculdade de Educação Física. Goiânia, Goiás, Brasil. Rod. Goiânia-Neropólis, Km 12, Campus Samambaia - Samambaia. CEP: 74001-970.

3 Universidade Federal de Minas Gerais. Faculdade de Educação. Belo Horizonte, Minas Gerais, Brasil. Av. Antônio Carlos, nº 6627 - Pampulha. CEP: 31270-901. 


\begin{abstract}
This article aims to analyze how $\mathrm{PhD}$ theses and Master dissertations present sexual education in the State of Goias. On the one hand, we seek to investigate what insights are embedded in the public schools and, on the other hand, we sought to analyze how sexuality in the school has been shown in the scientific production of the State. In our discussion of those productions, we established as criteria works which had been defended by 2012, and also thought of or realized in the context of State Schools and which dialogued with the theme in vogue. It became evident that sexuality has very much attracted the interest of professionals of the health field and of the education field as well. These specific fields present in their discourses which "knowledge" should be taught and who is considered able to teach that subject at schools, disputing the best ways to teach sexuality.

Keywords: sexuality schooling; sexuality in the school; theoretical productions about sexuality at the schools in the State of Goiás.
\end{abstract}

A sexualidade vem sendo escolarizada no Brasil dos mais variados modos, e não sem conflitos e disputas. Por um lado, movimentos sociais organizados lutam para que o assunto seja discutido na escola com o objetivo de fazer com que as diferenças sexuais sejam reconhecidas e valorizadas ${ }^{4}$. Por outro lado, algumas políticas públicas demandam essa escolarização em um claro esforço para colocar a sexualidade sob controle ${ }^{5}$. Com diferentes demandas em torno do tema, as escolas se veem forçadas a trabalhar a sexualidade, apesar das dúvidas e das dificuldades que o assunto acarreta. Como efeito decorrente, encontramos, atualmente, inúmeras tentativas de se trabalhar o tema da sexualidade no contexto escolar. Contudo, não se sabe, ao certo, que tipos de saberes sobre a sexualidade são priorizados, silenciados ou ignorados ${ }^{6}$. Por isso, resolvemos investigar as dissertações e teses sobre sexualidade que realizaram pesquisas empíricas nas escolas de Goiás, no intuito de mapear e compreender como a escolarização da sexualidade vem ocorrendo no estado ${ }^{7}$.

4 Alguns exemplos de estudos decorrentes de grupos do estado de Goiás: Gonçalves (1998); Borges (1999); Mello et al. (2011); Mello, Avelar e Maroja (2012); Mello et al. (2013); Gonçalves, Pinto e Borges (2013).

5 Exemplos de estudos nesse sentido: Monteiro (1999); Brasil (1997, 1999, 2012); Gomes e Vieira (2010).

6 Essa ideia foi parcialmente inspirada em Guacira Louro (2001).

7 A pesquisa que subsidia este artigo foi desenvolvida por Aline Nicolino, sob a supervisão de Marlucy Paraíso, durante o seu Estágio Pós-Doutoral realizado no programa de Pós-Graduação Conhecimento e Inclusão Social em Educação da UFMG em 2013. 
Por escolarização da sexualidade compreendemos o processo por meio do qual a sexualidade é tema "intencionalmente" e "explicitamente" ensinado na escola ${ }^{8}$. Consideramos que uma função primordial da escola e do seu currículo é a de ensinar. Como mostra Paraíso (2011, p. 147), o "currículo é espaço de ensino por excelência [...] Ensinar é transmitir, informar, apresentar, expor, explicar, explicitar". Ao escolarizar a sexualidade é necessário torná-la um tema ensinável na escola, e isso ocorre em meio a disputas, conflitos e relações de poder. O objetivo deste artigo, portanto, é o de trazer alguns dados das investigações mapeadas e estudadas para analisar como vem ocorrendo a escolarização da sexualidade no estado de Goiás, identificando quais saberes já foram escolarizados e quais precisam tornar-se transmissíveis, explicáveis e exercitáveis para ganhar espaço nos currículos escolares.

Cabe registrar aqui que os estudos analisados não trabalham explicitamente com a noção de escolarização da sexualidade ${ }^{9}$. Contudo, consideramos que o que encontramos nas investigações aqui analisadas, em seu conjunto, foi exatamente um esforço por mostrar que saberes sobre a sexualidade vêm sendo ensinados, incluindo: como se ensina sexualidade nas escolas, quem ensina, que dificuldades se encontram, que estratégias são adotadas nesse ensino, etc. Isso, portanto, nos possibilita pensar sobre o que vem ocorrendo quando a sexualidade passa a integrar a escolarização.

Como docente da disciplina de Estágio Curricular Supervisionado em escolas públicas na cidade de Goiânia/GO foi possível, para uma de nós, identificar os inúmeros conflitos ocorridos no meio escolar, em diferentes momentos, diante da "obrigação" de se ensinar sobre sexualidade. Isso já despertou interesse em compreender melhor o tema. A participação em grupos de estudos, eventos científicos e a aproximação com membros de movimentos sociais fortaleceram a vontade de investigar, para melhor compreender e mapear quais conhecimentos têm sido priorizados nas escolas públicas da cidade, quais saberes estão sendo silenciados e por quê.

8 Forquin (1992) já mostrava o processo complexo que envolve a seleção, transformação, escolarização e ensino dos saberes incorporados nos currículos escolares. Esse processo tem recebido, no campo do currículo e da educação, diferentes nomes: didatização, mediação didática, escolarização e transposição didática. É o processo de ensino de saberes relativos à sexualidade na escola, assim como as disputas envolvidas no processo, as seleções e exclusões feitas e as estratégias adotadas nesse ensino, portanto, que denominamos escolarização da sexualidade.

9 O que temos percebido ao mapear a produção sobre a sexualidade na escola é que tratar explicitamente e conceitualmente da escolarização da sexualidade é lacunar nas pesquisas sobre sexualidade na escola. Isso deve receber nossos esforços de conceitualização em nossos próximos estudos. 
Durante o acompanhamento do estágio, circulavam comentários entre as/os docentes e gestoras/es sobre a falta de registros, documentos e propostas permanentes e duradouras no estado de Goiás para tratar das questões da sexualidade na escola. Além disso, uma pesquisa realizada sobre essa temática com coordenadoras/es das Secretarias de Educação e Saúde, municipais e estaduais, com grupos de pesquisas e ONGs da cidade $^{10}$, identificou a pouca atuação do estado em políticas educacionais voltadas para as questões de sexualidade de modo mais amplo, especialmente no ensino público de Goiânia/GO (NICOLINO et al., 2013). Uma concepção abrangente da sexualidade na escola envolve "[...] conhecimentos e práticas sociais voltadas ao cuidado com o corpo, a uma vivência consciente e prazerosa da sexualidade [...]", para além dos discursos de prevenção e medicalização do corpo (UNBEHAUM; CAVASIN; GAVA, 2010, p. 9).

Já no contexto científico brasileiro, há uma avaliação mais positiva no que se refere ao aumento das publicações sobre gênero e sexualidade no campo da educação. É possível identificar, no período entre 1998 e 2004, uma considerável elevação em número de pesquisas (teses, dissertações e artigos) sobre esses assuntos (SILVA; NETO, 2006; VIANNA et al., 2011). Estatisticamente, a produção sobre gênero, sexualidade e educação formal passou de 16 estudos realizados no ano de 1990 para 193 em 2004, o que representa um crescimento de 12 vezes (VIANNA et al., 2011). Outro dado interessante é que em 2004 a atenção sobre essa temática triplicou, se comparada aos três anos anteriores, na região Centro-Oeste (TORRES; GULO, 2010).

Nesse panorama, a produção acadêmica sobre gênero e sexualidade nas políticas públicas educacionais é também objeto de um estudo de Vianna (2012), que faz levantamentos das teses, dissertações e artigos realizados. O estudo mostra que as primeiras publicações surgem no ano de 1995 e somente em 2002 se constatou a defesa de uma tese de doutorado. No período de 2001 a 2003 foram encontradas 14 publicações e entre 2004 e 2006, foram 16. Contudo, entre 2007 e 2010 foi verificado um aumento significativo: um total de 36 publicações sobre o tema ( 2 artigos, 27 dissertações de mestrado e 7 teses de doutorado). Apesar de a autora considerar a produção ainda tímida, é possível identificar um movimento crescente da produção sobre gênero e sexualidade nas políticas públicas escolares, concentrado, sobretudo, nas regiões Sul e Sudeste do país (VIANNA, 2012).

10 Pesquisa intitulada "Desafios e possibilidades das identidades de gênero e sexualidade na escola: ampliando e pluralizando ações educativas", financiada pelo edital n 20/2010 do Conselho Nacional de Desenvolvimento Científico e Tecnológico (CNPq), no período de 2011 a 2012. 
Contudo, apesar de todo o interesse que a temática vem suscitando, não sabemos ao certo como tem sido tratada a sexualidade nas escolas, e nem o que as pesquisas empíricas realizadas nesse campo vêm analisando e mostrando. É essa lacuna que este artigo pretende preencher ao estudar o assunto no estado de Goiás. A reflexão procura expor o tensionamento existente entre os saberes que são demandados e aqueles que são operacionalizados. Assim, buscamos investigar quais ensinamentos estão sendo inseridos nas escolas públicas de Goiás por meio das análises das dissertações e teses que estudaram o tema e realizaram pesquisas empíricas nas escolas do estado. Consideramos que questionar os argumentos que fomentaram tais investidas acadêmicas pode nos dar "pistas" para problematizar as verdades produzidas nesses materiais e compreender quais são suas diretrizes. Há nos estudos sobre sexualidade um campo de conhecimento e abordagem com maior prioridade? Há oposição ou complementaridade entre os estudos acadêmicos sobre sexualidade e as práticas escolares sobre a sexualidade? Quais campos vêm se ocupando de pesquisar a sexualidade? E que áreas/profissionais/disciplinas vêm se ocupando de ensinar a sexualidade nas escolas de Goiás?

Diante dos investimentos e das "verdades" que circulam sobre a temática nas escolas públicas estaduais, de um lado temos as/os docentes que sentem dificuldades em trabalhar a sexualidade na escola e operam no silêncio e, de outro, professoras/es guiando-se por discursos religiosos e/ou prescritivos para intervir pedagogicamente.

Tendo em vista essas questões, portanto, analisamos nas produções - que são objeto de estudo da pesquisa que dá base para este artigo - o campo de estudo no qual se inserem, o modo como abordam o tema, as justificativas de suas formulações, os objetivos, as dificuldades e as possibilidades de trabalho com o tema que elas apontam. Por meio de avaliações do que indicam essas teses e dissertações, argumentamos que há, em Goiás, um contexto histórico marcado por iniciativas públicas pontuais e descontínuas no que se refere a documentar e potencializar ações voltadas para a escolarização da sexualidade. As poucas iniciativas encontradas em algumas escolas recebem investimentos governamentais para implantar projetos que ainda priorizam os discursos epidemiológico e alarmista no campo pedagógico (NICOLINO, 2012). Assim, para analisar tais questões, problematizamos: Que necessidades mobilizam as dissertações e teses produzidas sobre o tema? Quais as finalidades dessas pesquisas? Quais os discursos produzidos? Essas produções apontam limites e possibilidades da escolarização da sexualidade nas escolas do estado de Goiás?

Tais indagações nos levam a outras questões, uma vez que na área da saúde é possível identificar os frutos que as justificativas epidemiológicas produziram, especialmente com o advento da aids. O Programa Saúde e Prevenção 
nas escolas (SPE) parece ser mais um dos investimentos governamentais das últimas décadas para abordar a sexualidade na escola de modo a vinculá-la com a necessidade de lidar com as doenças sexualmente transmissíveis (DSTs), como a aids, e com a gravidez na adolescência (SILVA; NETO, 2006; UNBEHAUM; CAVASIN; GAVA, 2010).

Diante desse contexto, o argumento desenvolvido neste artigo é o de que, no conjunto das produções analisadas, ficaram evidentes aproximações e distanciamentos entre os campos da educação e da saúde para se trabalhar com a sexualidade no contexto escolar. Aproximações, por ambos os campos, consideram que é importante investir na formação docente. Distanciamentos, por apresentarem formas distintas de trabalhar com a sexualidade na escola. $\mathrm{O}$ campo da educação propõe inserir o tema de maneira transversal no processo de formação docente, para que tais discussões sejam feitas de forma coletiva, por meio de conteúdos que tratam das questões social, cultural e histórica. O campo da saúde propõe que o ensino sobre a sexualidade seja mediado por um/a profissional da área da saúde inserido/a no contexto escolar. Propõe ainda que a sexualidade seja ensinada por meio de conteúdos que tratam das questões epidemiológicas e preventivas das doenças sexualmente transmissíveis, assim como a gravidez e o uso de drogas. Portanto, tanto os estudos do campo da saúde quanto os da educação apresentam quais "saberes" devem ser ensinados e quem pode ensinar o tema na escola, disputando as melhores formas para escolarizar a sexualidade no estado de Goiás.

É possível, assim, identificar esforços e investimentos nas discussões que permeiam a sexualidade no contexto escolar. Contudo, tais políticas ainda se encontram centradas em discursos alarmistas de prevenção (ARILHA; CALAZANS, 1998), voltados para uma "normatização da sexualidade e da reprodução" (KNAUTH et al., 2006, p. 405). Esses discursos também podem ser problematizados com base nas lutas e demandas contemporâneas por políticas públicas para a população LGBT $^{11}$ no Brasil. Mello, Avelar e Maroja (2012, p. 294) apontam dificuldades na sua implementação e explicam que a falta de instrumentos jurídicos articula-se com as peculiaridades do campo da sexualidade. Afinal, tais políticas têm como "[...] ponto de partida a necessidade de mudança de crenças, valores e tradições [...]". Aliado a isso, apontam que outra dificuldade existente é a pouca efetivação de planos e programas, com escassez de recursos e falta de entrosamento entre formuladoras/es e executoras/ es (MELLO; AVELAR; MAROJA, 2012).

11 No Brasil, a sigla LGBT se refere a lésbicas, gays, bissexuais, travestis e transexuais (CARRARA, 2010). 
Em outras palavras, o aumento da produção científica e do investimento público em projetos e ações ainda não garantiu o desenvolvimento de políticas públicas em sexualidade que atendam as demandas de áreas e grupos marginalizados. Além disso, a discussão ainda é incipiente no contexto escolar. Como consequência, as/os professoras/es encontram dificuldades para trabalhar as questões de sexualidade e gênero em sala de aula (SILVA; NETO, 2006; UNBEHAUM; CAVASIN; GAVA, 2010).

$\mathrm{Na}$ pesquisa que subsidia este artigo, foi feito um levantamento das produções sobre o tema por meio de buscas no banco de teses e dissertações do Portal Capes, além dos sites das bibliotecas de universidades públicas e privadas do estado de Goiás, que ofereciam cursos de pós-graduação (stricto sensu) nas mais diferentes áreas do conhecimento. Também foram feitas visitas nessas instituições, de forma a levantar todas as produções voltadas para a discussão da sexualidade na escola. Para a apreciação dessas produções, estabelecemos como critérios o tempo, o espaço e a temática, ou seja, terem sido defendidas até 2012, serem pensadas ou realizadas no contexto escolar do estado de Goiás e dialogarem com a temática em pauta.

Valemo-nos dos descritores "educação sexual", "sexualidade", "orientação sexual" e "educação em sexualidade", combinados ainda com as palavras "escola" e "educação", além do termo "escolarização da sexualidade". Ao todo, foram encontradas 23 dissertações e teses. Após a leitura dos textos, selecionamos para análise 10 produções que contemplavam os critérios adotados e que dialogavam diretamente com o objeto em questão: foram nove dissertações e uma tese.

Quanto às pessoas que se dedicaram a estudar a sexualidade no contexto escolar, 90\% das autorias desses trabalhos são de mulheres. Encontramos apenas um autor homem. Com relação à cronologia das produções, a primeira foi publicada no ano de 1998, seguida por outras em 1999, 2001 e 2004. Entre os anos de 2007 e 2012 as produções foram sequenciais, ou seja, quase uma produção por ano, em um total de cinco dissertações e uma tese, com exceção do ano de 2009, que não teve nenhum trabalho defendido.

TABELA 1 - SISTEMATIZAÇÃO POR ÁREA DE CONHECIMENTO DAS PRODUÇÕES DE TESES E DISSERTAÇÕES/GO

\begin{tabular}{|c|c|c|c|c|}
\hline \multicolumn{2}{|c|}{ Área de Conhecimento } & Mestrado & Doutorado & $\%$ \\
\hline \multicolumn{2}{|c|}{ Educação } & 6 & & $60 \%$ \\
\hline \multirow{3}{*}{ Saúde } & Enfermagem & 2 & & $20 \%$ \\
\hline & Medicina Tropical & 1 & & $10 \%$ \\
\hline & Ciências da Saúde & & 1 & $10 \%$ \\
\hline \multicolumn{2}{|l|}{ Total } & 9 & 1 & $100 \%$ \\
\hline
\end{tabular}


Observa-se que duas áreas têm estudado a temática: a educação e a saúde. Isso ocorre com disputas e conflitos, já que circulam discursos muito diferentes nesses dois campos para pensar, falar e para trabalhar com a sexualidade. E são exatamente esses interesses divergentes, as abordagens distintas e as diferentes justificativas apresentadas pelos estudos analisados que passaremos a mostrar.

\section{As justificativas e os objetivos anunciados nas dissertações e tese analisadas}

Para analisar os discursos produzidos e divulgados nas dissertações e na tese sobre a escolarização da sexualidade, em Goiás, problematizamos as justificativas apresentadas para sua elaboração. De uma maneira geral, os trabalhos partem de um diálogo direto com os contextos investigados, seja pela atuação profissional, seja pelos contatos estabelecidos com as escolas. $\mathrm{O}$ fato de esses trabalhos serem, em sua maior parte, do campo da educação, pode ser explicado pela grande circulação do interesse, dos questionamentos e dos conflitos que interpelam o tema nas escolas. Contudo, a interlocução feita pelos/as autores/as desses trabalhos com profissionais da área da saúde, principalmente enfermeiras, também foi representativa nessas produções, apontando para uma crescente participação e interesse dessas/es profissionais pelo meio escolar para divulgação de seus saberes.

A maior parte das justificativas dos trabalhos está relacionada com o desejo de compreender as diferentes manifestações das sexualidades presentes nos contextos escolares, que ora se apresentam em situações de conflito, ora são representadas por dúvidas e questionamentos, ora expressas pela falta de ação e/ou silenciamento por parte das/os docentes. Os discursos sobre a sexualidade que operam nessas práticas pedagógicas foram apresentados nas produções sob duas perspectivas. Uma delas direcionada para a articulação entre a sexualidade e as dimensões social, cultural e política nas práticas educativas, como pode ser observado no estudo de Silva (2001), ao justificar o incômodo que sentia ao ver a forte presença da educação sexual nos rituais e intervenções pedagógicas, "[...] por vezes, explicitamente religiosa, ou na interdição/negação da sexualidade como parte fundamental da vida humana." (SILVA, 2001, p. 15). A outra perspectiva se incomodava com falas, perguntas e brincadeiras presenciadas na educação infantil. Silveira (2010), por exemplo, afirma que docentes e funcionárias/os relatavam não saber lidar com questões sexuais das crianças, manifestadas nas falas e na reprodução do que vivenciavam em suas casas. Os 
comentários que circulavam eram de que as crianças tinham uma sexualidade aflorada e precoce por presenciar relações sexuais de seus pais ou responsáveis (SILVEIRA, 2010).

As pesquisas de Gonçalves (1998), Carvalho (2004) e Sobral (2008) também se esforçam para relacionar as discussões social, cultural e política com a escolarização da sexualidade. O primeiro estudo apresenta e avalia o processo de formação docente e discente (GONÇALVES, 1998); o segundo discute a produção de subjetividades de crianças divulgadas pela mídia televisiva (CARVALHO, 2004) e o terceiro problematiza as questões da exploração sexual de meninas e seus desafios (SOBRAL, 2008). Todos eles, de alguma forma, contextualizam a importância dessas discussões no campo escolar e defendem a formação contínua e plural para lidar com o tema. Isso significa atender toda a comunidade escolar, especialmente as/os docentes. Além disso, consideram que é importante que se leve em consideração tanto os temas silenciados, tidos como tabus, quanto os saberes circulantes, como crenças religiosas e intervenções guiadas pelas experiências pessoais.

Cabe destacar que as estratégias metodológicas utilizadas para pesquisar e produzir determinados discursos diferenciam-se conforme a área em que os trabalhos se inserem. Nesse sentido, a maioria das produções realizadas no campo da educação utiliza como instrumentos de produção de dados o questionário, a entrevista, o grupo focal (CARVALHO, 2004; MARTINS, 2010) e o grupo de discussão (SILVEIRA, 2010), nas quais se valem da abordagem qualitativa para analisar as informações coletadas/produzidas. Tal abordagem é utilizada nesses estudos visando explicitar "os significados presentes na situação e nas formas particulares em que cada sujeito envolvido nela se encontra, além de trazerem à tona aquilo que experimentam, o modo como interpretam ou o sentido que dão à experiência vivida" (VILELA, 2003, p. 460).

Já nas pesquisas realizadas na área da saúde, há, claramente, o uso de abordagens epidemiológicas articuladas com estratégias metodológicas intervencionistas na investigação sobre a escolarização da sexualidade. Assim, com a justificativa da necessidade de uma intervenção, uma enfermeira aponta as dificuldades enfrentadas pelas/os professoras/es ao trabalhar a temática orientação sexual no ambiente escolar, desenvolvendo práticas pedagógicas educativas centradas na prevenção (SOUZA, 2007). Outra enfermeira refere que o fato de acompanhar diversas famílias que enfrentam a problemática da gravidez na adolescência a motivou a trabalhar medidas urgentes de intervenção com esse grupo (CHAVEIRO, 2011). No mesmo sentido, Queirós (2012) justifica sua pesquisa pela necessidade de reduzir as vulnerabilidades de jovens às DSTs e à gravidez não planejada. 
Todos os trabalhos do campo da saúde utilizaram a abordagem qualitativa para orientar seus procedimentos metodológicos, anunciando que as interpretações e análises dos dados estariam articuladas com um sistema de significados sociais do período investigado. Tal estratégia visa apresentar as demandas e as singularidades do contexto analisado que, segundo Neves (1996), contribui para uma melhor compreensão do fenômeno. Portanto, valer-se do discurso de uma abordagem qualitativa é, ao mesmo tempo, valer-se de uma determinada "legitimidade" do método científico, que supostamente abarcaria "todas" as possibilidades de interpretação e análise do empírico. Já a abordagem quantitativa é utilizada para levantamentos que justificam posições de intervenção e prescrição no meio escolar. Somente um estudo contemplou uma análise quantitativa representativa, compondo sua amostra com 1.662 estudantes de escolas públicas da cidade (MONTEIRO, 1999). Contudo, cabe mencionar que o trabalho de Chaveiro (2011) foi realizado em seis escolas, por meio do questionário entregue a um total de 79 docentes. Os outros dois concentraram-se em uma amostra menor, sendo que Souza (2007) e Queirós (2012) realizaram suas pesquisas em uma escola, com um grupo reduzido de participantes, fazendo uso de questionário, entrevista e grupo focal.

Fica evidente que as justificativas apresentadas nos trabalhos operam em duas lógicas, que por vezes se aproximam, por vezes se afastam. Uma lógica é a que podemos chamar de sociopolítica, centrada no campo da educação, que articula questões sociais, culturais e políticas com os dados empíricos produzidos nas escolas, valendo-se dessa mediação para pensar, problematizar e, em alguns casos, intervir nas escolas investigadas. A pesquisa desenvolvida por Gonçalves (1998) contextualiza e avalia duas experiências de formação continuada com docentes e discentes, podendo exemplificar tal lógica, em que se apresenta a escolarização da sexualidade sob as lentes das ciências humanas.

A segunda lógica, operada nas pesquisas do campo da saúde, é nomeada de comportamental ${ }^{12}$, por se apropriar dos conhecimentos técnicos em Enfermagem, especialmente da esfera epidemiológica da saúde, para dialogar e por vezes direcionar as formas de vivenciar, manter e construir uma sexualidade "saudável". Isso pode ser visto no trabalho de Chaveiro (2011), que para contextualizar um mundo em transformações, situa o jovem em uma situação de vulnerabilidade $^{13}$ às drogas e às doenças. Este estudo defende a ideia de "[...]

12 Monteiro (1999); Souza (2007); Chaveiro (2011) e Queirós (2012).

13 O conceito é empregado pela autora com base nos estudos de Nichiata et al. (2008), no sentido de superar a lógica de risco epidemiológico, buscando avançar na discussão dos determinantes sociais que permeiam a produção dos agravos. Assim, é "apontada como um conjunto de aspectos que vão além do individual, abrangendo aspectos coletivos, contextuais, que levam à suscetibilidade a doenças ou agravos" (MUÑOZ SANCHEZ; BERTOLOZZI, 2007, apud CHAVEIRO, 2011, p. 25). 
uma intervenção urgente, no sentido de preparar este jovem para viver de forma mais saudável" (CHAVEIRO, 2011, p. 26).

A aproximação entre as duas perspectivas se dá pela articulação entre as questões sociais e políticas que são apresentadas como ponto de partida para entender e analisar a realidade investigada, assim como pela imersão no contexto para coletar/produzir os dados. Contudo, a visão conceituada como sociopolítica busca nesta interlocução os elementos que podem contribuir no processo de formação do grupo. Já a comportamental, por sua vez, defende a presença da/o profissional da saúde nesse processo de formação.

É possível identificar também aproximações entre as produções do campo da saúde e da educação ao compreenderem a escola como um espaço "apropriado" para a discussão da sexualidade. No campo da saúde, isso é justificado com base nas diretrizes do SPE (2006, p. 15), que justifica a inserção do tema no espaço escolar com dados estatísticos sobre a quantidade de "adolescentes e jovens entre 10 e 24 anos de idade (62\%)" que frequentam a escola por ser este um espaço comprometido com a "transformação da realidade econômica, política, histórico-cultural”. Com essas justificativas, os trabalhos na área da saúde atribuem grande importância ao fazer a "promoção da saúde" na escola. Já no campo da educação, fundamenta-se a institucionalização do debate sobre a sexualidade no contexto escolar, por meio de questões levantadas principalmente pelos movimentos feministas, com fortes críticas à hierarquia de gênero. Tais estudos, na contramão das pesquisas da saúde, questionam as "regras de higiene e saúde que concorrem para a formação de corpos saudáveis e disciplinados" (CÉSAR, 2009, p. 52), os quais constituem um investimento em uma determinada "norma" desejada para meninos e meninas (LOURO, 2001). Portanto, apesar de ambos os campos defenderem a institucionalização da escolarização da sexualidade, as perspectivas teóricas utilizadas são distintas. A saúde justifica sua entrada pela medicalização do corpo e a educação por colocar-se contrária a essa disciplinarização.

Para analisar os objetivos formulados pelas pesquisas, partimos do pressuposto de que há aproximações e distanciamentos entre os estudos sobre o tema da escolarização da sexualidade entre os campos da educação e da saúde. Em um primeiro levantamento, apresentam finalidades próximas, como "conhecer", "compreender", "descrever" e "construir" a educação sexual ou trazer o tema para o discurso coletivo como uma possibilidade de articular a prática pedagógica com o campo do conhecimento científico. Contudo, ao analisarmos as finalidades das produções no campo educacional, identificamos diferenças significativas, já que tais trabalhos visam "[...] analisar quais os mecanismos que determinam a sexualidade e como a determinam [...]; compreender o papel da instância socializadora e o seu alcance na perspectiva emancipadora" (SILVA, 
2001, p. 13); "conhecer e analisar como as/os professoras/es compreendem e se posicionam diante da sexualidade das crianças", além de "identificar as ações e as políticas públicas para a educação infantil sobre o tema" (SILVEIRA, 2010). Trata-se de identificar, problematizar e dialogar sobre o tema, não para prescrever como fazer, mas para ampliar e transversalizar o debate no espaço escolar, de forma reflexiva e questionadora.

Nas produções da saúde, por sua vez, os objetivos voltam-se para investigar, identificar, diagnosticar, conhecer, analisar e " [...] construir, com os professores, diretrizes sobre a temática orientação sexual para que possam utilizá-las na construção e implementação do Projeto Político Pedagógico". (SOUZA, 2007, p. 40). Visam também averiguar conhecimentos, crenças e comportamentos sexuais adotados sobre DST/aids e a prevalência do uso de preservativos (MONTEIRO, 1999). Portanto, sob uma perspectiva mais intervencionista, tais estudos identificam conflitos e dificuldades sobre o tema na escola e, a partir desse levantamento, desenvolvem ações e apontam diretrizes.

Uma pesquisa significativa nesse sentido foi a dissertação de Monteiro (1999), que realizou um estudo transversal em 36 escolas públicas da rede estadual de Goiânia por meio da aplicação de questionário para 1.662 estudantes de 15 a 24 anos. Os dados, conforme destaca a pesquisadora, evidenciam que as/os estudantes não consideram a abstinência uma forma de prevenção, pois segundo ela "[...] foi baixo o índice de acertos (32\%), no item que se refere à abstinência sexual como forma de prevenção da aids". Afirma também que, apesar de conhecerem as formas de transmissão e infecção do HIV, suas concepções são errôneas, pois "indicam um entendimento incompleto sobre padrões de transmissão da doença”. Além disso, para a autora, as/os estudantes apresentam "alta prevalência de início sexual precoce, de multiplicidade de parceiros durante a vida, de sexo anal e baixo uso de preservativo" (MONTEIRO, 1999, p. 51 e 87).

Essa pedagogia da sexualidade, nos termos de Louro (2001, p 41), que "legitima determinadas práticas sexuais e reprime outras", pode estar sugerindo uma falta de interlocução dos/as autores/as desses trabalhos com os estudos sobre gênero, classe, etnia e as análises culturais, sociais, políticas e históricas. Com base nesse raciocínio, a falta de conduta indicada por Monteiro (1999) pode estar sinalizando poucas possibilidades de negociação e de decisão no modo como o tema é apresentado para as/os adolescentes. Além disso, evidencia a fragilidade das abordagens prescritivas e moralizantes da sexualidade. 


\section{As dificuldades apontadas pelos estudos para trabalhar com a sexualidade no contexto escolar}

As dificuldades em lidar com as questões da sexualidade no contexto escolar são discutidas nas dissertações e na tese analisadas, tanto nas justificativas apresentadas para o seu desenvolvimento quanto nas conclusões dos trabalhos. Três principais dificuldades são anunciadas nas produções. A primeira refere-se aos diversos atravessamentos de discursos de diferentes campos que o tema da sexualidade recebe ao ser trabalhado no cotidiano escolar. Nesse sentido, a família, a religião, as mídias e as determinações legislativas são entendidas como importantes interlocutoras para tratar o tema. Apesar dos levantamentos mostrarem que os saberes sobre sexualidade são delimitados e produzidos no contexto escolar, os estudos reforçam a importância de se considerar os conhecimentos científicos ou técnicos sobre o tema, assim como os aspectos sociais, históricos, culturais e políticos nas mediações pedagógicas estabelecidas para se trabalhar a sexualidade.

Essa observação pode ser identificada em alguns trabalhos que verificaram que a maior parte das/os docentes se vale de saberes do senso comum, principalmente de suas vivências e crenças do campo religioso, para fundamentar suas intervenções (GONÇALVES, 1998; CARVALHO, 2004) e trabalhar o tema na escola. De modo geral, foi possível constatar nas produções analisadas que as mediações pedagógicas com as/os estudantes e com a comunidade escolar fundamentam-se em um discurso conservador, pautado em um moralismo judaico-cristão. Isso pode ser visto em Silva (2001); Sobral (2008); Martins (2010) e Silveira (2010).

Além disso, as/os docentes referem-se à sexualidade das adolescentes por meio de valores morais, posicionando-se "[...] de forma preconceituosa, moralista, embasando seus argumentos apenas no pensamento religioso", com dificuldades para analisar as mensagens e situações sob uma perspectiva laica (MARTINS, 2010, p. 109). Tal estudo também mostra que, apesar de o ensino público ser “[...] laico, permanece ainda a herança da ascendência religiosa em relação a tabus, sobretudo católicos, no tocante à sexualidade, incluindo a descoberta do próprio corpo" (MARTINS, 2010, p. 121). Essa atitude das/os docentes, que a autora chama de "moralista", tem como apoio teórico a compreensão da sexualidade como doença, prevalecendo "[...] a concepção de que a sexualidade precisa ser controlada e vigiada, mas não estudada e compreendida" (MARTINS, 2010, p. 133). Tais levantamentos mostram as dificuldades das/os docentes em contextualizar as questões sociais, políticas e culturais do tema. E essa sem dúvida é uma dificuldade que o tema da sexualidade encontra para ser escolarizado. 
A segunda dificuldade para a escolarização da sexualidade anunciada nas produções analisadas está articulada com a anterior e se refere à insuficiente formação docente. Todos os estudos defendem a necessidade de ações contínuas nesse aspecto. No que se refere ao processo de formação, os trabalhos apontam para a falta de informações das/os educadoras/es a respeito das questões do assunto. Alguns defendem a introdução de uma disciplina no currículo das licenciaturas para suprir alguns conceitos e questionamentos de gênero e sexualidade. Sobral (2008), por exemplo, defende que há uma necessidade de orientadores/ as sexuais na educação infantil. Contudo, para a autora, esses/as orientadores/ as precisam receber uma formação específica e continuada.

Na mesma direção, Monteiro (1999, p. 41), ao defender a “[...] necessidade em se investir em educação sexual na escola e de iniciá-la precocemente", sugere que é necessário ainda subsidiar programas com informações e conhecimentos científicos em DST/aids. Atrelada à formação inicial, a formação continuada é proposta nesses estudos como uma ação que propicia espaço para a discussão dos conhecimentos científicos, de modo a estabelecer um diálogo com os sujeitos, para que as experiências sejam refletidas e ampliadas com a discussão coletiva.

A terceira dificuldade em lidar com o tema da sexualidade na escola também dialoga com as anteriores e se refere ao que chamam de escassez de políticas educacionais e falta de continuidade de projetos que pautam a temática. Assim, os trabalhos analisados apontam que esforços, investimentos e ações construídas são extintos com a entrada de um novo governo no poder. As experiências ficam restritas ao grupo que as produziu, em suas memórias. A história é reconstruída a cada governo, sem o conhecimento do passado. Nessa direção, Gonçalves (1998), por exemplo, identifica uma ausência de incentivo político e uma falta de diálogo entre Secretarias, Estado, governo federal e comunidade escolar como grandes dificuldades que a escolarização da sexualidade enfrenta.

Quanto à sistematização de propostas elaboradas no âmbito nacional, Sobral (2008) avalia os Parâmetros Curriculares Nacionais (PCNs), especificamente o caderno "Pluralidade Cultural e Orientação Sexual", e argumenta que o documento não contribui para uma mudança de concepção e pensamento, pois apenas oferece algumas orientações e informações. Além disso, identifica que, apesar de propor o tema de forma transversal, o material não transforma as representações sociais de sexualidade das/os professoras/es. Consequentemente, para o autor, por ser um material que apenas oferece algumas orientações, os PCNs não contribuem para um trabalho significativo de educação sexual na escola (SOBRAL, 2008).

Nessa mesma direção, Souza (2007) verificou que a orientação sexual prevista pelos PCNs não é discutida de forma sistemática dentro da escola. Além disso, ela não faz parte das grades curriculares das grandes escolas e colégios do 
município de Goiânia. Como constatou com sua pesquisa, "[...] somente alguns professores de biologia estão abordando conteúdos específicos na área da sexualidade como anatomia do corpo humano, prevenção de doenças de transmissão sexual, métodos contraceptivos e reprodução" (SOUZA, 2007, p. 33).

Outro aspecto levantado pelos estudos analisados a respeito das políticas educacionais é a inexistência de conhecimentos nos currículos que discutem a exploração sexual comercial de adolescentes. O estudo de Martins (2010), por exemplo, verificou que, mesmo a temática sendo percebida pela gestão e pelo corpo docente da escola, não há nenhum tipo de intervenção que discuta o assunto. O silenciamento, para a autora, já se instaura no processo de formação dessas/es educadoras/es, continua com a falta de denúncia e encaminhamentos no âmbito escolar e finaliza com a ocultação do assunto nos documentos oficiais da instituição e no projeto político-pedagógico (PPP) da escola. As dificuldades, para a autora, são efeitos da falta de apoio governamental, o que tem como consequência a escassez de políticas públicas de proteção e de defesa contra a exploração sexual (MARTINS, 2010).

Apesar de um balanço negativo sobre como a escola atua e da falta de políticas públicas voltadas para o processo de formação docente referente à sexualidade nas escolas em Goiás, denunciadas em parte significativa dos estudos, esses também apresentam algumas possibilidades de diálogo. É isso que abordaremos a seguir.

\section{Escolarização da sexualidade: as possibilidades apontadas pelos estudos analisados}

A maior parte dos estudos analisados aponta possibilidades de trabalhar a sexualidade na escola. Contudo, é interessante notar que se inspiram nas dificuldades encontradas para trabalhar o tema, para falar dos desafios que a sexualidade na escola deve enfrentar. Assim, práticas pedagógicas que se valem de saberes populares, crenças religiosas, experiências individuais e ausência de políticas educacionais foram os desafios mais recorrentes apontados nas produções. A descrição e a avaliação de experiências exitosas, em grande parte, são anunciadas em intervenções realizadas durante as pesquisas. Para apresentar possibilidades do tema na escola, portanto, são apresentados dois contextos. Um anterior à pesquisa, marcado pelos conflitos e limites das abordagens do tema, e outro, posterior, marcado pelas possibilidades que o assunto pode gerar na escola, por meio da mediação de conhecimentos científicos e de pessoas "qualificadas" para fazê-lo. 
Nessa direção, os estudos do campo da saúde apresentaram a proposta de "educação em saúde" como a melhor estratégia para mudar os altos índices de infecção e disseminação de DSTs. A proposta parte de dados "alarmantes" apresentados nessas produções, em que a figura da/o enfermeira/o é apresentada como essencial para o diálogo entre a escola e as instituições governamentais e não governamentais. Essa união visa, conforme defende Souza (2007), por exemplo, "[...] construir uma rede integrada de saúde e educação com foco na redução dos possíveis problemas à saúde do educando de hoje, além de contribuir para a formação de futuros cidadãos saudáveis". (SOUZA, 2007, p. 162).

A articulação entre escola e saúde, segundo Chaveiro (2011), deve abranger as/os profissionais que atuam na Estratégia e Saúde da Família (ESF) ${ }^{14}$ como interlocutoras/es no meio escolar. A intervenção de enfrentamento às vulnerabilidades de jovens na rede de ensino pauta-se em ações de promoção, prevenção e atenção à saúde. Como descreve Chaveiro (2011, p. 26), “[...] é necessário que educadores e profissionais da ESF assumam de fato seu papel como educador e que estejam mobilizados e habilitados para o trabalho na área da sexualidade com foco na informação em saúde, na prevenção". Queirós (2012) reforça a importância da integração família, escola e saúde com ênfase na enfermagem, no sentido de promover a saúde integral das/os escolares, por meio da continuidade dos programas governamentais (SPE e PSE).

No campo da educação, a formação profissional inicial e continuada é apresentada como um importante recurso de aprendizagem, problematização e reflexão sobre a sexualidade da escola. As justificativas nesse sentido consideram as dimensões técnica, cultural, histórica, social, estética e política como essenciais no processo de escolarização da sexualidade. Além disso, consideram fundamental a criação de espaços de debates coletivos na escola para as questões de gênero e sexualidade. Nesse sentido, Silva (2001, p. 114), por exemplo, propõe que "[...] cada escola possa pensar e se organizar na troca de experiências" sobre o tema. Considera-se também que é preciso que tais momentos façam parte de uma política educacional permanente, com sistematizações no PPP e interlocuções com as Secretarias de Educação, municipal e estadual e com políticas públicas nacionais (GONÇALVES, 1998).

Ainda defendendo a necessidade da capacitação docente para o trabalho com o tema da sexualidade, alguns estudos da área da educação defendem a inclusão de uma educação voltada para a discussão dos valores humanos como prioritários no processo de formação docente. Consideram necessário pensar

14 O ESF visa integrar família, escola e saúde com ênfase à enfermagem, “[...] no sentido de promover a saúde integral dos adolescentes escolares e continuidade dos programas governamentais, Saúde e Prevenção nas Escolas [SPE] e o Programa Saúde na Escola [PSE]”' (QUEIRÓS, 2012, p. 14). 
em projetos que incorporem os "[...] conteúdos de gênero, de sexualidade, de raça, de violência, entre outros, para que se amplie a compreensão a respeito dos alunos e das alunas" (MARTINS, 2010, p. 132). Essa ampliação é proposta por entender que as escolas estão em "[...] situações precárias de existência, sobretudo, pelo fato de estarem empobrecidas em suas relações humanas" (GONÇALVES, 1998, p. 165). O estudo de Silveira (2010, p. 139), na mesma direção de defesa da capacitação docente, mostra que é preciso contemplar na formação "[...] valores como a amizade, amor, carinho, atenção, companheirismo, lealdade, dignidade, respeito, fé".

Entre as possibilidades apresentadas nas produções, identificamos duas lógicas discursivas distintas. De um lado, o campo da saúde faz a defesa de um/a enfermeiro/a para promover "cidadãos saudáveis", em uma espécie de rede integrada entre saúde e educação, por meio de investimentos governamentais (SPE e PSE). De outro, o campo da educação defende a formação continuada e os grupos de estudo e trabalho no espaço escolar como momentos coletivos importantes de trocas e debates entre as/os professoras/es para que o tema seja tratado de modo adequado. Apesar de ambos defenderem a formação docente continuada, regulamentada em uma política pública de Estado, a saúde advoga por um/a profissional da área da saúde para trabalhar com a sexualidade nas escolas, e a educação defende a diversidade profissional e o diálogo coletivo como estratégias do processo de capacitação do/a docente nas escolas para o trabalho com o tema.

\section{Breves considerações}

Foi possível constatar na pesquisa aqui apresentada que há divergências nos discursos dos campos da educação e da saúde quando se pretende trabalhar a sexualidade na escola. Embora ambos tenham possibilitado o levantamento, o registro e a avaliação das questões da sexualidade na prática pedagógica e promovido espaços sistematizados de reflexão e diálogos entre a comunidade escolar, os dois campos defendem o ensino de saberes distintos sobre a sexualidade, apresentam as dificuldades que as escolas enfrentam para trabalhar a sexualidade de modo diferente e se diferenciam também ao apresentar as possíveis estratégias para o trabalho com a sexualidade na escola.

$\mathrm{Na}$ área educacional, os trabalhos se esforçaram em defender a importância de se trabalhar os conteúdos de gênero e sexualidade no currículo das licenciaturas e na formação continuada dos/as professores/as. Além disso, descrevem as dificuldades que docentes e diretoras/es sentem, valendo-se por vezes do 
silenciamento como prática e guiando-se por saberes diversos (família, religião, mídias, epidemiologia). O discurso da precariedade do processo de formação docente, ocasionado pela falta de investimentos governamentais e, consequentemente, de políticas públicas é utilizado tanto para denunciar certo "descaso" do governo com o tema, como para apresentar as dificuldades em lidar com a sexualidade na escola.

Contudo, tais posicionamentos aparecem nas produções por se compreender que a escola é a instituição que deve ser responsável por desenvolver o assunto. Há demandas apresentadas nos campos acadêmico, político e social pela escolarização da sexualidade. Apesar de exporem perspectivas teóricas e finalidades distintas, todos partem do pressuposto de que o espaço escolar é o "mais apropriado" para o debate e a reflexão sobre o tema. Essa responsabilização da escola pelo trabalho com a sexualidade implica em "cobrar" de professoras/ es e dirigentes condutas inseridas em uma discussão que envolve os estudos de gênero, feministas, culturais e dos direitos humanos. Portanto, ao mesmo tempo em que se defende o espaço escolar como espaço privilegiado para o trabalho com a sexualidade; denuncia-se a formação docente, que é considerada inadequada para o preparo dos/as docentes e dirigentes que trabalham o tema na escola.

Essa "cobrança" por debates e pessoas "qualificadas" também pode ser problematizada pelo uso do discurso que ora estigmatiza, ora potencializa a discussão do tema da sexualidade nas escolas públicas de Goiás. É estigmatizada quando opera com preceitos e orientações religiosas que permeiam as instituições pesquisadas, por meio de falas, olhares, linguagens e rituais religiosos. É potencializada em diretrizes do Ministério da Saúde, por meio de prescrições sobre a necessidade do uso de preservativos associados ao medo de uma gravidez na adolescência e/ou de infecção por DST/aids, frequentemente. Contudo, tais discursos não estão operando de forma linear e isolada. Os discursos "permitidos" nas aulas de Ciências, por exemplo, são apropriados e ressignificados, por vezes dentro de uma moral religiosa cristã, por vezes por suas experiências familiares, por vezes midiáticas, por vezes ainda pelas discussões científicas operantes.

Nesse sentido, os estudos da área da saúde apresentam orientações e prescrições de como se deve trabalhar a sexualidade na escola. Várias dessas orientações são baseadas em discursos epidemiológicos. Sob o pretexto de formar "indivíduos saudáveis", essas investigações no campo da saúde aqui analisadas valem-se de estudos que fundamentam suas intervenções frente à gravidez indesejada, à infecção por HIV/aids e ao uso de drogas.

O discurso científico é utilizado para capacitar educadoras/es e, ao mesmo tempo, para atestar a importância da inserção da/o profissional da saúde na escola, visando ampliar seu espaço de trabalho. Já os estudos da educação apresentam a necessidade de uma formação inicial e continuada, vista a "legitimidade" dos 
discursos constituídos pelos saberes populares, experiências pessoais e religiosas, que se (re)produzem cotidianamente nas práticas pedagógicas.

Assim, ficou muito evidente na análise dos estudos aqui apresentados que as pesquisas consideram que há uma carência na formação docente e de políticas educacionais adequadas para que a escolarização da sexualidade ocorra de modo satisfatório. Ficou evidente também a existência de divergências entre os campos da saúde e da educação sobre qual é (ou deve ser) o/a profissional mais capacitado para trabalhar a sexualidade na escola. Enquanto a educação defende a pluralidade profissional e o debate coletivo para articular práticas pedagógicas com as necessidades de cada realidade escolar, os estudos da saúde defendem a/o profissional da própria área como essencial para o processo de escolarização da sexualidade, sob a justificativa de produzir corpos "saudáveis". Portanto, é possível identificar relações de poder em ambos os campos de conhecimento, que se traduzem em discursos diferenciados sobre as dificuldades enfrentadas pela escolarização da sexualidade e em possibilidades também diferenciadas para que a temática seja trabalhada na escola. Contudo, é comum nas pesquisas de ambos os campos a demanda por um espaço para o tema no currículo escolar, ficando evidente que esse processo é marcado por tensões, disputas e conflitos, ao mesmo tempo em que há tentativas de diálogos e aproximações.

Em síntese, fica evidente que ainda são necessários muitos investimentos para que a sexualidade seja escolarizada de modo a possibilitar uma reflexão crítica sobre prazer, amor, convivência, trocas, afeto etc. O tema necessita que se faça muitos outros investimentos tanto em políticas educacionais e na formação de professoras/es, como na elaboração de materiais didáticos, curriculares e nas próprias práticas pedagógicas. Afinal, a sexualidade ainda se encontra em foco nas lutas e disputas sobre o que, como e porque ensiná-la. Ela ainda é tema que "luta para ganhar espaço nos currículos em ação das escolas" (PARAISO; SANTOS, 1996) e para ser, portanto, de fato escolarizado de modo a valorizar as diferenças e como foco de trocas de experiências, de compartilhamento de dúvidas e sensações.

\section{REFERÊNCIAS}

ARILHA, Margareth; CALAZANS, Gabriela. Sexualidade na adolescência: o que há de novo? In: Jovens acontecendo na trilha das políticas públicas. Brasília: Comissão Nacional de População e Desenvolvimento/CNPD, 1998. 
BORGES, Lenise Santana. Educação sexual nas escolas: Grupo Transas do Corpo. In: FARIA, Nalu (Org.). Cadernos Sempre Viva: gênero e educação. São Paulo: SOF, 1999. p. 55-66.

BRASIL. Ministério da Educação e do Desporto. Secretaria do Ensino Fundamental. Parâmetros Curriculares Nacionais: pluralidade cultural e orientação sexual. Brasília: MEC/SEF, 1997. Disponível em http://portal.mec.gov.br/seb/arquivos/pdf/livro101.pdf. Acesso em 01/02/2013.

BRASIL. Ministério da Saúde. Política Nacional de DST/Aids: princípios e diretrizes. Coordenação Nacional de DST e Aids. Brasília: Ministério da Saúde, 1999. Disponível em: $<$ http://www.ilo.org/wcmsp5/groups/public/ed_protect/protrav/ilo_aids/documents/ legaldocument/wcms_127698.pdf $>$. Acesso em: 23/02/2010.

BRASIL. Secretaria de Estado de Educação. Prevenção também se ensina na escola: sugestões de atividades preventivas para HTPC e sala de aula. São Paulo: Governo do Estado de São Paulo/Fundação para o Desenvolvimento da Educação. São Paulo: Diretoria de Projetos Especiais, 2012. Disponível em: $<$ http://file.fde.sp.gov.br/portalfde/ Arquivo/Arte_comunidade_prevencao.pdf $>$. Acesso em: 04/05/2013.

CARRARA, Sérgio. Políticas e direitos sexuais no Brasil contemporâneo. Revista Bagoas, n. 05, p. 131-147, 2010.

CARVALHO, Rita de Cássia. A sexualidade na interface criança - TV. Dissertação (Mestrado em Educação) - Faculdade de Educação. Programa de Pós-Graduação em Educação da UFG, Goiânia, 2004.

CÉSAR, Maria Rita de Assis. Lugar de sexo é na escola? Sexo, sexualidade e educação sexual. In: Sexualidade. Secretaria de Estado da Educação. Superintendência de Educação. Departamento de Diversidades. Núcleo de Gênero e Diversidade Sexual. Curitiba: SEED, 2009, p. 49-59.

CHAVEIRO, Laine Gomes. A temática sexualidade no contexto escolar: diagnóstico situacional da região leste de Goiânia, Goiás. Dissertação (Mestrado em Enfermagem) - Faculdade de Enfermagem. Programa de Pós-Graduação em Enfermagem da UFG, Goiânia, 2011.

FORQUIN, J. C. Saberes escolares, imperativos didáticos e dinâmicas sociais. Teoria \& Educação, Porto Alegre, n. 5. p. 28-49, 1992.

GOMES, Maria Rebeca Otero; VIEIRA, Nadjanara. Saúde e prevenção nas escolas: promovendo a educação em sexualidade no Brasil. Revista Tempus Acta em Saúde Coletiva, 2010. Disponível em: <https://docs.google.com/viewer?url=http://tempus.unb. br/index.php/tempus/article/viewFile/798/786\&chrome=true $>$. Acesso em: 08/04/2013.

GONÇALVES, Eliane. Educação sexual em contexto escolar: da formação de professores/as à sala de aula. Dissertação (Mestrado em Educação) - Faculdade de Educação. Programa de Pós-Graduação em Educação da UFG, Goiânia, 1998. 
GONÇALVES, Eliane; PINTO, Joana Plaza; BORGES, Lenise Santana. Imagens que falam, silêncios que organizam: sexualidade e marcas de homofobia em livros didáticos brasileiros. Currículo sem Fronteiras, v. 13, p. 35-61, 2013.

KNAUTH, Daniela; HEILBORN, Maria Luiza; BOZON, Michel; AQUINO, Estela M. L. Sexualidade juvenil: aportes para as políticas públicas. In: HEILBORN, Maria Luiza et al. (Orgs.). $O$ aprendizado da sexualidade: reprodução e trajetórias sociais de jovens brasileiros. Rio de Janeiro: Garamond e Fiocruz, 2006, p. 400-420.

LOURO, Guacira Lopes. Pedagogias da sexualidade. In: LOURO, Guacira Lopes (Org.). O corpo educado: pedagogias da sexualidade. 2. ed. Belo Horizonte: Autêntica, 2001, p. 7-34.

MARTINS, Railda Gonçalves. Os saberes docentes e a exploração sexual comercial de meninas: desafios da contemporaneidade. Dissertação (Mestrado em Educação) - Faculdade de Educação. Programa de Pós-Graduação em Educação da UFG, Goiânia, 2010.

MELLO, Luiz; BRAZ, Camilo; GONCALVES, Eliane; MURCE, Nilton F. Para uma educação que aceite e respeite as diferenças. Polyphonia: Revista de Educação Básica do Cepae (UFG), v. 22, p. 463-470, 2013.

MELLO, Luiz; AVELAR, Rezende Bruno de; MAROJA, Daniela. Por onde andam as políticas públicas para a população LGBT no Brasil. Sociedade e Estado, v. 27, n. 2, p. 289-312, 2012.

MELLO, Luiz; PERILO, Marcelo P.; BRAZ, Camilo Albuquerque de; PEDROSA, Cláudio Henrique. Políticas de saúde para lésbicas, gays, bissexuais, travestis e transexuais no Brasil: em busca de universalidade, integralidade e equidade. Rio de Janeiro, Sexualidad, Salud y Sociedad, v. 1, p. 7-28, 2011.

MONTEIRO, Luciene Cunha. Conhecimentos e crenças sobre DST/Aids e comportamento sexual em jovens de escolas públicas estaduais de Goiânia. Dissertação (Mestrado em Medicina Tropical) - Instituto de Patologia Tropical e Saúde Pública. Programa de Pós-Graduação em Medicina Tropical da UFG, Goiânia, 1999.

NEVES, José Luis. Pesquisas qualitativas - características, usos e possibilidades. São Paulo/SP, Caderno de Pesquisas em Administração, v. 1, n. 3, 2º semestre de 1996.

NICOLINO, Aline et al. Educação sexual e políticas públicas: limites e possibilidades das secretarias. In: NICOLINO, Aline et al. (Orgs.). Educação Sexual em Goiás. Goiânia: Editora PUC, 2013.

NICOLINO, Aline. Desafios e possibilidades das identidades de gênero e sexualidade na escola: ampliando e pluralizando ações educativas. Relatório de Pesquisa enviado ao $\mathrm{CNPq}$, referente ao Edital MCT/CNPq/SPM-PR/MDA n ${ }^{\circ}$ 020/2010, em dezembro de 2012 .

PARAÍSO, Marlucy; SANTOS, Lucíola. Dicionário crítico da educação: currículo. Presença Pedagógica, Belo Horizonte, v. 2, n. 7, p. 82-84, 1996. 
PARAÍSO, Marlucy. Raciocínios generificados no currículo escolar e possibilidades de aprender. In: LEITE Carlinda et al. (Orgs.). Políticas, fundamentos e práticas do currículo. Porto: Porto Editora, 2011, v. 1, p. 147-160.

QUEIRÓS, Pollyana de Siqueira. Concepções de pais de adolescentes escolares sobre temáticas relacionadas à sexualidade humana. Dissertação (Mestrado em Enfermagem) - Faculdade de Enfermagem. Programa de Pós-Graduação em Enfermagem da UFG, Goiânia, 2012.

SILVA, Aurora Helena Fidelis. Educação sexual na escola: a prevalência da moral burguesa e a possibilidade de construção da autonomia. Dissertação (Mestrado em Educação) - Faculdade de Educação. Programa de Pós-Graduação em Educação da UFG, Goiânia, 2001.

SILVA, Regina, C. P.; NETO, Jorge N. Formação de professores e educadores para a abordagem da educação sexual nas escolas: o que mostram as pesquisas. Ciência e Educação, v. 12, n. 2, p. 185-197, 2006.

SILVEIRA, Jennifer Martins. Manifestações da sexualidade da criança na educação infantil: estranhamentos e desafios. Dissertação (Mestrado em Educação) - Faculdade de Educação. Programa de Pós-Graduação em Educação da UFG, Goiânia, 2010.

SOBRAL, Osvaldo José. Representações sociais de sexualidade dos professores da Educação Infantil e dos anos iniciais do Ensino Fundamental. Dissertação (Mestrado em Educação) - Faculdade de Educação. Programa de Pós-Graduação em Educação da UFG, Goiânia, 2008.

SOUZA, Márcia Maria de. Construindo a inclusão da temática educação sexual no projeto político pedagógico de um colégio público de Goiânia-Goiás na perspectiva da pesquisa-ação. Tese (Doutorado em Ciências da Saúde) - Convênio Rede CentroOeste UFG/UNB/UFMT. Programa de Pós-Graduação em Ciências da Saúde, UFG/ UNB/UFMT, 2007.

SPE. Saúde e Prevenção nas escolas: diretrizes para implementação do Projeto. Saúde e Prevenção nas escolas. Ministério da Saúde. Secretaria de Vigilância em Saúde. Brasília: Série Manuais, $\mathrm{n}^{\circ} 77$, julho de 2006. Disponível em: <http://sistemas.aids.gov.br/ saudenaescola2010/sites/default/files/Diretrizes_de_Implementacao.pdf $>$. Acesso em: 23/9/2013.

TORRES, Taluana Laiz Martins; GULO, Fábio Henrique. Gênero, sexualidade e exclusão: as diferenças em debate nos saberes em educação. Fazendo Gênero: diásporas, diversidades, deslocamentos, 2010. Disponível em: < http://www.fazendo genero.ufsc.br/9/resources/anais/1277936329_ARQUIVO_FAZGENERO2010completo-final\%5B1\%5D\%5B1\%5D.pdf $>$. Acesso em: 4/4/2013.

UNBEHAUM, Sandra; CAVASIN, Sylvia; GAVA, Thais. Gênero e sexualidade nos currículos de pedagogia. Fazendo Gênero: diásporas, diversidades, deslocamentos, 2010. Disponível em: <http://www.fazendogenero.ufsc.br/9/resources/anais/1278171100_ ARQUIVO_Gen_Sex_Curric_Ped_ST19_FG9.pdf>. Acesso em: 27/5/2013. 
VIANNA, Claudia Pereira et al. Gênero, sexualidade e educação formal no Brasil: uma análise preliminar na produção acadêmica entre 1990 e 2006. Revista Educação \& Sociedade, Campinas, v. 32, n. 115, p. 525-545, abr./jun. 2011.

VIANNA, Cláudia Pereira. Gênero, sexualidade e políticas públicas de educação: um diálogo com a produção acadêmica. Pro-Posições, Campinas, v. 23, p. 253-278, 2012.

VILELA, Rita Amélia Teixeira. O lugar da abordagem qualitativa na pesquisa educacional: retrospectiva e tendências atuais. Perspectiva, Florianópolis, v. 21, n. 02, p. 431-466, jul./dez. 2003.

Texto recebido em 19 de maio de 2014.

Texto aprovado em 20 de maio de 2014. 